\title{
Akıllı Tarımda Sensör Uygulaması
}

\author{
Erdinç Öztürk ${ }^{1}$, Yavuz Çelik ${ }^{2}$, Pınar Kırc1 $^{3^{*}}$ \\ 1.2 Bursa Uludag Üniversitesi, Mühendislik Fakültesi, Bilgisayar Mühendisliği Bölümü, Bursa, Türkiye \\ $3^{3 *}$ Bursa Uludag Üniversitesi, Mühendislik Fakültesi, Bilgisayar Mühendisliği Bölümü, Bursa, Türkiye, pinarkirci@uludag.edu.tr
}

(1st International Conference on Applied Engineering and Natural Sciences ICAENS 2021, November 1-3, 2021)

(DOI: $10.31590 /$ ejosat.1013749)

\begin{abstract}
ATIF/REFERENCE: Öztürk, E., Çelik, Y. \& Kırcı, P. (2021). Akıllı Tarımda Sensör Uygulaması. Avrupa Bilim ve Teknoloji Dergisi, (28), 1279-1282.

$\ddot{O} \mathbf{z}$

Nüfus artışının, iklim değişikliklerinin ve küresel ısınmanın etkileri ile birleşen kaliteli tarımsal ürün yetiştirme sorununun yanında daha düşük maliyetle daha kaliteli ürün yetiştirme arayışı tarım sektöründe sorunların üstesinden gelebilmek için teknolojinin imkanlarını kullanma zorunluluğunu beraberinde getirmiştir. Bu konuda yapılan çalışmalar Akıllı Sera sistemlerinin bu sorunların çözümünde önemli rol oynadığını göstermiştir. Çalışmamızda, Arduino kontrollü bir Akıllı Sera düzeneği hazırlanmıştır. Çalışmamızda, sera kontrolünün otonom olmasının yanında gerekli durumlarda bluetooth teknolojisi kullanılarak Akıllı seranın mobil cihazlarla uzaktan kontrolü de sağlanmıştır. Akıllı Sera ortamındaki veriler sensörlerle okunup hazırlanan yazılımla kontrol edilerek 1sıtma, soğutma, sulama gibi müdahaleler istenildiği durumda otomatik, istenildiği durumda da geliştirilen Android uygulama yardımıyla manuel olarak da gerçekleştirilmiştir.
\end{abstract}

Anahtar Kelimeler: Akıllı sera, tarım, iklim değişikliği, arduino, sulama.

\section{Sensor Application in Smart Agriculture}

\begin{abstract}
The effects of population growth, climate changes and global warming have revealed the problem of growing quality agricultural products. In addition, the pursuit of growing higher quality products at lower costs has revealed the necessity of using the possibilities of technology in agriculture. Studies have shown that Smart Greenhouse systems are important in solving these problems. In our study, an Arduino-controlled Smart Greenhouse has been prepared. In addition to the autonomous control of the greenhouse, remote control of the smart greenhouse with mobile devices is also provided by using bluetooth technology when necessary. The data in the Smart Greenhouse environment were read by sensors. These data were controlled by the prepared software and interventions such as heating, cooling and irrigation were carried out automatically when requested, or manually with the help of the developed Android application when desired.
\end{abstract}

Keywords: Smart greenhouse, agriculture, climate change, arduino, irrigation. 


\section{Giriş}

Dünyanın değişik bölgelerinde ve değişik iklim şartlarında yapılan çalışmalar küresel ve yerel olarak tarım alanında yaşanan sıkıntıların çözümünde akıllı teknolojilerin kullanılmasını çok önemli hale gelmiştir.

Yapılan çalışmaların önemli bir amacı da tarıma elverişli arazilerin dışında akıllı sera ortamlarında tarımsal ürünlerin yetiştirilmesini sağlamaktır. Bu sayede uygun toprak ve iklim koşullarını oluşturarak akıllı sistemlerle kontrol edilen seralarda tarımsal ürünlerin yetiştirilmesi ve insanların bu ürünlere erişimin kolaylaştırılması önemli bir araştırma ve uygulama konusu olmuştur. Modern ve geleneksel tarım uygulamalarının uygulanabilirliğini karşılaştırarak modern tarıma geçişin hızlandırılması amacıyla birçok çalışma yapıılmıştır.

[1]'de, Arduino UNO mikrodenetleyicisine dayalı bir serada patates çeşitlerinin bakımı ve yaşanan ihtiyacın daha verimli şartlarda karşılanabilmesi için bir çözüm olabilmesi amacıyla prototip ölçeğe sahip otomatik bir sera sistemi tasarlanmıştır. Yapılan çalışmada, çıkış aktüatörlerinin performansının sensörden elde edilen giriş değeri ile uygunluğunu test edilmiştir. Yapılan çalışma sonucunda sistemin bir bütün olarak iyi çalıştığ görülmüştür.

Yapılan çalışma, Cezayir'deki yaşanan su sorunu ifade edilmiş, tarım sektörünün toplam su kullanımının $\% 70$ oranla ilk kullanıcısı olması nedeniyle su tasarrufu sağlayarak verimli ürün yetiştirme konusunda suyun en uygun şekilde kullanımını sağlamayı hedeflemiştir. $\mathrm{Bu}$ konunun çözümünde akıllı teknolojilerin kullanılmasının uygun olacağı ifade edilmiştir. İncelenen çalışmada, tarım arazileri için su kullanımını optimize etmek ve çiftçinin tarlasını kontrol edebilmesine yardımcı olmak için bulut teknolojisi ve Arduino mikrodenetleyicisine dayalı otomatik bir sulama sistemi önerilmiştir [2].

Bu çalışmada, Akıllı serada iklim kontrolünü sağlamak amacıyla Akıllı Bulanık Mantık tabanlı bir kontrol sistemi kullanılmıştır. Üzerinde yer alan ve birbirine bağlı olan değişkenlerin sayısı nedeniyle karmaşık bir işlem olan sera iklim kontrolü bu yöntemle kontrol edilmeye çalışılmıştır. Yapılan çalışmada, oluşturulan mikro iklim ortamı sayesinde sıcaklık ve nemin en uygun şekilde ayarlanabilmesi için özel ölçümler yapılmıştır. Bu kapsamda önerilen kontrol sistemi deneysel olarak doğrulanarak sistemin enerji ve su tasarrufu gösterilerek verimliliği değerlendirilmiştir [3].

Yapılan çalışmada, Arduino tabanlı akıllı sulama sistemi çalışması yapılmıştır. Çalışma, tarıma dayalı bir ülke olan Hindistan'da kalabalık nüfusu beslemenin zorluğunu gözönünde bulundurarak özellikle pirinç üretiminde ak1llı seralarda akıllı sulama sistemlerinin kullanılması üzerine kurulmuştur. Çalışmada, düşük maliyetli ve kullanımı kolay Arduino tabanlı bir kontrollü sulama sistemi çalışması yapılmıştır. Yıllar geçtikçe akıllı teknolojinin yükselişi ile birlikte gerek tarımda insan çabalarını azaltma çabalarıyla birlikte su kaynakları ve güç tüketimini azaltma ihtiyacı gerekse hızla yaşanan nüfus artışının etkisiyle artan gıda taleplerinin karşılanabilmesi bakımından ekonomik şartlarda kaliteli ürün yetiştirme amacıyla çiftçilere destek verebilmesi için akıllı sulama sistemleri ve akıllı sera çalışmaları hız kazanmıştır [4].

Yapılan çalışmada Arduino kullanan IoT tabanlı akıllı sera otomasyonu çalışması yapılmıştır. Çalışmada, serada büyümeyi artırmak verileri analiz etmek ve buna göre sistemi kontrol etmeyi hedeflemiştir. Sistemde, Arduino mikrodenetleyici ve ona uygun yazılım ve sensörler kullanılmıştır. Arduino Mega kartı kullanılarak tasarım yapılmış, sensörlerin sulama amacıyla toprak nemini ve seranın 1şık yoğunluğunu ölçmesi hedeflenmiştir. Çalışmada, akıllı sera tasarımlarında kontrol sisteminin temel aşamaları; sensörler aracılığıyla verilerin toplanması, verilerin işlenmesi ve istenen durumlarla karşılaştırılması ve son olarak sistemin durumunu değiştirmek için ne yapılması gerektiğine karar verilmesi olarak ifade edilmiştir [5].

Çalışmada, nem sensörü kullanılarak Arduino tabanlı otomatik sulama sisteminin Android ișletim sistemli akıllı cihazlar üzerinden uzaktan kontrolü incelenmiştir. Bu çalışmada, uzaktan kumanda için Android işletim sistemli akıllı cihazları kullanan ekonomik ve kullanımı kolay, Arduino tabanlı otomatik bir sulama sistemi geliştirilmiştir. Sistem tasarımı yapabilmek amacıyla, çeşitli toprak türlerinin ve belirli ürünlerin incelenmesi ve yapılan örneklemelerin sonucunda elde edilen değerlerden elde edilen verilerin serada kullanılan topraktan elde edilen nem içeriğiyle orantılı bir toprak nem sensörü kullanılmıştır [6].

$\mathrm{Bu}$ projede, yaşanan bu gelişmeler ışığında gelişen teknolojiye ayak uydurabilmek amacıyla "Akıllı Tarım, Akıllı Sera" alanında bir çalışma yapılmıştır. Bu amaçla, akıllı sera prototipi oluşturularak belirlenen iklim şartlarına uygun şekilde programlanmış, elde edilen veriler ışığında geliştirilmesi amaçlanmıştır. Projede, öncelikle bu konuda yapılmış olan çalışmalar incelenmiştir. Akıllı teknolojilerin tarımda ve seralarda kullanılmasının gerekliliği, incelenen çalışmalarda görülmüştür. Yapılan araştırmalarda akıllı tarım uygulamasının hangi ortamlarda, ne şekilde verim sağlayacağı konusunda incelemeler yapılmıştır. İncelemeler sonucunda oluşturulan prototip üzerinde testler yapılarak güncellemeler gerçekleştirilmiştir.

\section{Materyal ve Metot}

Bu projede, akıllı sera prototipinin oluşturularak ak1llı sera ve doğal ortamda yetiştirilecek aynı bitkilerin gelişmelerinin izlenerek sonuçların analiz edilmesi ve bu kapsamda ne gibi geliştirmelerin yapılabileceğini belirlenmesi esas alınmıştır. Bunun yanısıra aynı sera ortamında yetiştirilen çiçek ve sebze bitkilerinin gelişimlerinin takip edilerek aynı serada farklı bitkiler yetiştirilebilmesi konusunda bir ön çalışma yapıllmıştır.

Çalışmada, yapılan araştırmalardan sonra işlem basamakları şu şekilde belirlenmiştir. Kullanılacak materyallerin belirlenmesi, Akıllı seranın fiziki prototipinin oluşturulması ve gelişimleri izlenecek bitkilerin tespiti, Uygun devre tasarımı, Arduino Uno mikrodenetleyiciye uygun yazılımın geliştirilmesi, Appinverter ile mobil uygulama geliştirilerek sera değerlerinin takip edilmesi, Verilerin analiz edilerek sonuçlarının değerlendirilmesi.

Çalışmada, akıllı sera prototipini oluşturabilmek ve kontrol edebilmek için kullanılan malzemeler, malzemelerin genel özellikleri ve kullanım amaçları aşağıdaki açıklanmıştır.

Çalışmamızda, bir Adruino Uno mikrodenetleyici kart kullanılmıştır. Arduino, bir giriş/çıkış (I/O) kartı olarak son yıllarda yaygın olarak kullanılan elektronik bir donanım ve yazılım temelli önemli bir mikrodenetleyicidir.

Sera prototipine akıllı sıfatının eklenmesinde en büyük payı olan elemanlar serada kullanılan sensörlerdir. Sensörler, algılayıcı olarak da ifade edilebilir. Akıllı cihazların ortam değişkenlerinin kontrol edilmesinde sensörler önemli rol oynamaktadır. 
Sensörlerden alınan bilgiler ortamın sıcaklık, nem, 1Sı, basınç gibi değerlerinin analiz edilebilmesi amaciyla yazılımlara sunulmaktadır. Bu bilgilerden de anlaşılacağı üzere sensörler sera içindeki ortamı anlamamızda bize yardımcı olacak duyu organlarımızdır. Çalışmamızda, sera içinde sıcaklık durumunu ölçmek için DHT11 sensörü kullanılmıştır.

Projemizde kullanılan diğer bir sensör ise toprak nem sensörüdür.

Hazırladığımız akıllı sera prototipin Android tabanlı mobil cihazlarla iletişimi ve manuel olarak kontrolü için bluetooth bağlantısı kullanılmıştır. Bu amaçla, HC-06 Arduino bluetooth sensörü kullanımıştır.

Sera üzerinde biri büyük diğeri küçük olmak üzere hava akışını sağlayacak şekilde 2 adet kablolu plastik çarklı fan kullanılması planlanmıştır.

Projemizde kullandığımız sulama sisteminde $12 \mathrm{~V}$ ile çalışan firçasız dalgıç su pompası kullanılması planlanmıştır.

Ayrıca, seramik 1sitıcıya benzer bir seramik 1sitıcı lamba kullanılmıştır.

\section{Araştırma Sonuçları ve Tartışma}

Sera prototipi üzerinde sensor kablolarının girişi çıkışı, havalandırma fanlarının konumu ve kabloların yerleşimi, 1sıtıcı devrenin yerleşimi, sulama sisteminin konumu ve aydınlatma gibi dikkat edilmesi gereken birçok husus titiz bir şekilde planlanmıştır.

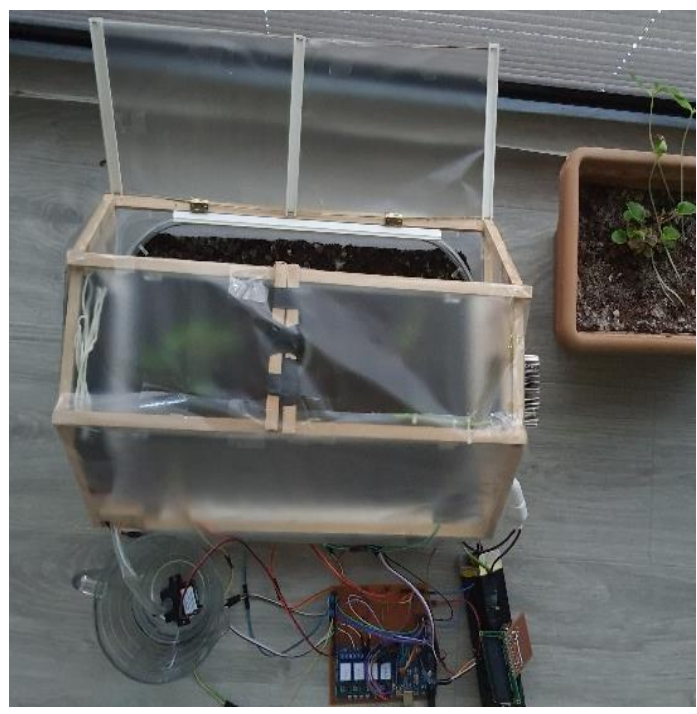

Şekil 1 Sera prototipi

Sera prototipinin üzeri Şekil 1'de görüldüğü gibi açılır kapanır şekilde yapılmıştır. Bu sayede, gerektiğinde üstü açılarak hem güneş 1şığından hem de ortam sıcaklığından faydalanılabilmesi sağlanmıştır.

Sera zeminine köklerin zarar görmemesi için eşdeğer özelliklerde ponza taşından zemin hazırlanmıştır. Hazırlanan zemin üzerine eş değer nitelikte toprak ve bir miktar solucan gübresi eklenmiştir. Yapılan araştırmalar sonucunda seraya, yaklaşık olarak aynı ortamlarda yetişen domates, biber ve salatalık bitkileri ile bunlarla yaklaşık aynı değerlerde yetişen begonya çiçeği ekilmesinin gözlem açısından uygun olacağ sonucuna varılmıştır.

\section{Sonuç}

Bitkilerin ekiminden sonra ilk fotoğraflar Şekil 2'de görüldüğü gibi elde edilmiştir. Bu kapsamda çalışmalar devam ettirilmiştir. Ayrıca, ilk sulamalar can suyu olması amacıyla el ile yapilmıştır.

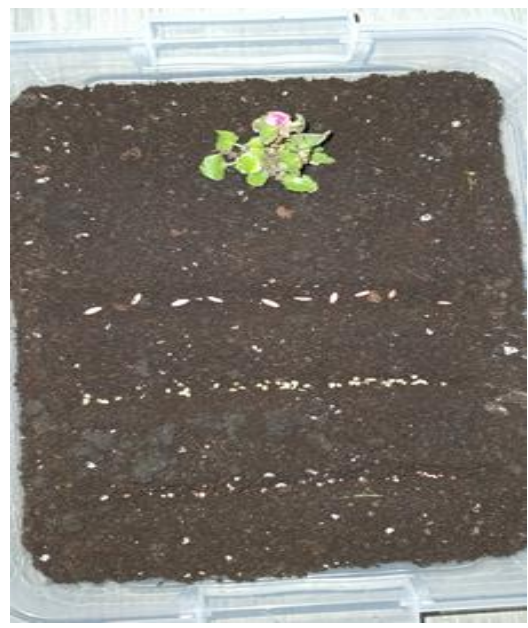

Şekil 2 Belirlenen düzene uygun olarak ekilen bitkiler

Hazırlanan prototipe uygun olarak oluşturulan sistem tüm bileşenlerin eklenmesiyle yazılımla kontrol edilebilir hale getirilmiştir.

Sistemin kontrolü amacıyla serayı çalışır hale getirebilmek için Arduino ile yazılım kontrolü sağlanmıştır. Yazılım için Arduino arayüzü kullanılmış ve sistemin otonom olarak çalışması sağlanmıştır. Yazılım oluşturulurken Arduino IDE arayüzü kullanılmıştır. Ayrıca, sistem istendiğinde Android tabanlı mobil cihazlar ile manuel çalışmasını sağlamak için bir arayüz oluşturulmuştur.

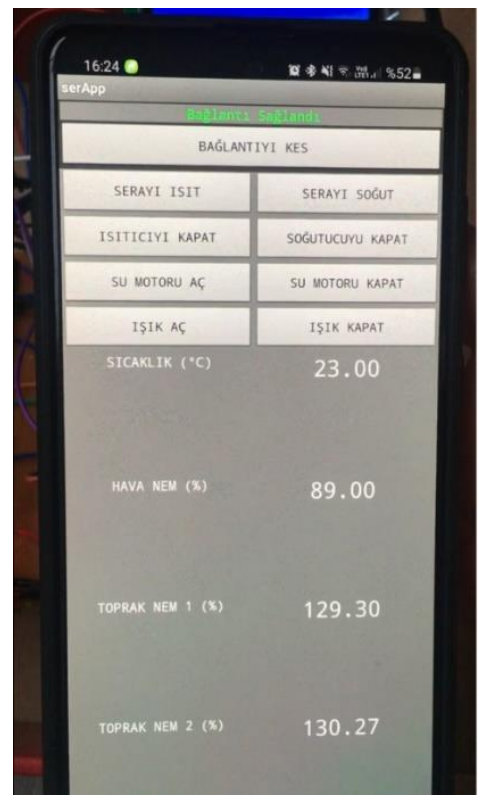

Şekil 3 Bağlantı sağlandıktan sonra verilerin okunarak uygulamada gösterilmesi 
Sistemin sensörlerden aldığı değerlere bağlı olarak şekil 3 de görüldüğü gibi su pompasını, 1sıtma ve soğutma sistemlerini gerektiğinde duruma göre Açık/Kapalı konumuna getirerek çalıştırması ve LCD panelin sürekli ekrana bilgileri yansıtması sağlanmıştır.

Elde edilen sonuca göre hazırlanan Akıllı Sera, begonya, domates ve biber gelişiminde olumlu olarak fark yaratmıştır. Salatalık ise saksıda daha çok büyümüştür. Yaptığımız çalışmada, bitkilerin akı1lı serada özellikle daha canlı olduğunu görme imkânımız olmuştur. Bu da verimin akıllı serada olumlu bir şekilde etkileneceğini göstermektedir.

Tüm bunların yanında, Akıllı Sera sistemimizin gerek kontrol edilebilirliği gerekse kullanışlı olması açısından faydalı bir çalışma olarak görülmüştür. Sistemin hem manuel hem de otonom olarak çalışabilir olması serayı kontrol eden kişi açısından büyük kolaylık sağlamaktadır. Ayrıca, seraya uzaktan erişimin olması da uzaktan kontrol sağlayarak dilediği müdahaleyi yapma firsatı bulmuştur. Bu sayede sistemin belli bir rutin dışında kontrol edilmesi gerektiğinde manuel kullanımı mümkün olmaktadır.

\section{Kaynakça}

[1] Sari, I.A., Lestari, A.N.H.D., 2018, "Smart Greenhouse sebagai Media Pembibitan Kentang Granola Kembang Berbasis Mikrokontroler", Prosiding Seminar Nasional Teknologi Elektro Terapan, Vol. 02 No. 01, ISSN: 25810049.

[2] Benyezza, H., Bouhedda, M., Djellout, K., 2018, "Smart Irrigation System Based Thingspeak and Arduino", 2018 International Conference on Applied Smart Systems (ICASS 2018), Algeria.

[3] Azaza, M., 2016, "Smart green house fuzzy logic based control system enhanced with wireless data monitoring", ISA Transactions 61, 297-307.

[4] Singh, P., Saikia, S., 2016, "Arduino-Based Smart Irrigation Using Water Flow Sensor, Soil Moisture Sensor, Temperature Sensor and ESP8266 WiFi Module", 2016 IEEE Region 10 Humanitarian Technology.

[5] Shirsath, D.O., Kamble, P., Mane, R., Kolap, A., More, R.S., 2017, "IOT Based Smart Greenhouse Automation Using Arduino", International Journal of Innovative Research in Computer Science \& Technology (IJIRCST), ISSN: 23475552, Volume-5, Issue-2, March 2017.

[6] Arvindan, A. N., Keerthika, D., 2016, "Experimental Inverstigation Of Remote Control Via Android Smart Phone Of Arduino-Based Automated Irrigation System Using Moisture Sensor", 3rd International Conference on Electrical Energy Systems. 